\title{
María Eugenia Pinto Claude: Maestra de la Infectología Chilena
}

\author{
María Eugenia Pinto Claude: Master of Infectious Diseases in Chile
}

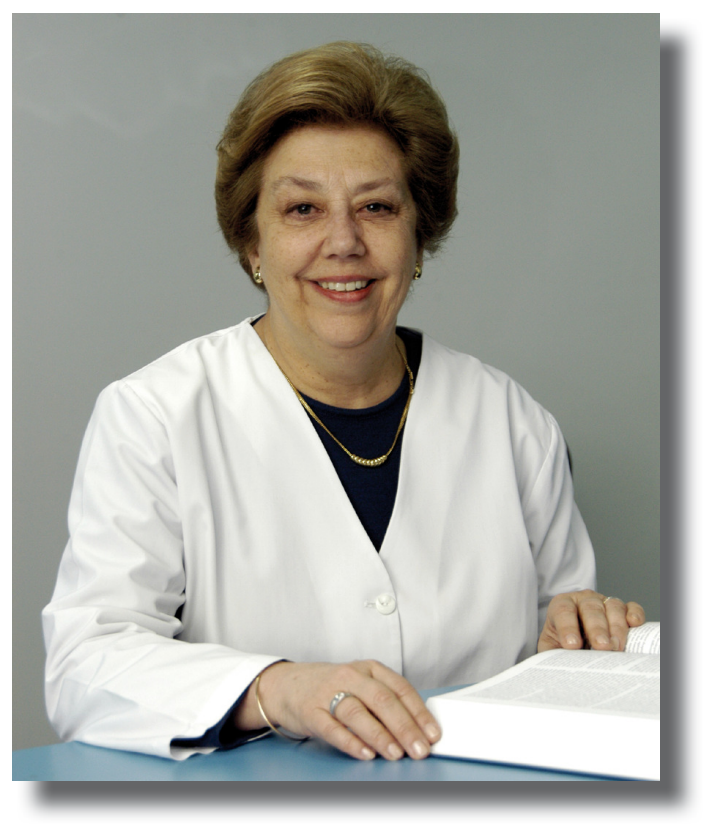

La Sociedad Chilena de Infectología ha establecido recientemente la distinción "Maestro (a) de la Infectología Chilena" para reconocer la trayectoria y gravitación en la especialidad de profesionales en el seno de nuestra sociedad cientifica.

Con ocasión del XXVII Congreso anual efectuado en Valdivia entre el 17 y 19 de noviembre reciente, se ha entregado este titulo honorifico, por primera vez, a la Dra. M. Eugenia Pinto C. A continuación una reseña de su trayectoria notable y aporte a la especialidad.

$\mathrm{H}$ ija de un destacado ingeniero civil, Don Ernesto Pinto Lagarrigue, gran empresario, ministro de Obras Públicas en el gobierno de Don Jorge Alessandri Rodríguez y de Luciana Claude Fonck, de origen francés, una mujer extremadamente culta y dedicada por entero a su familia. De su padre heredó sus condiciones humanas, inteligencia emocional, su sentido lógico, su sobresaliente capacidad organizativa, y de su madre el amor por el arte y la música. Casada con el Dr. Augusto Schuster Cortés, destacado y reconocido Profesor de Pediatría, con quien forma una maravillosa familia, constituida por sus cuatro hijos, Juan Eduardo, Macarena, María Paz y Andrés, quienes le han dado numerosos nietos. El Dr. Schuster además de ser pediatra es un microbiólogo de corazón, ya que siempre integró la Microbiología con la clínica marcando una tendencia que años después se materializaría en el médico infectólogo. Así pues, el amor por la Microbiología, en la Dra. Pinto se inició bajo la presión motivadora de su marido, quien ha sido a través de los años su apoyo incondicional y ferviente admirador.

Egresada de las Monjas Francesas, estudió Medicina en la Pontificia Universidad Católica, obteniendo el título de Médico Cirujano en 1967. Cinco años más tarde, luego de dedicarse a su familia, se especializa en Microbiología Clínica en la Universidad de Chile, Sede Occidente y en 1978 obtiene una beca del gobierno de Francia como Residente en el Hospital Saint Joseph, Universidad de París. Entre 1973 y 1995 se desempeñó como Jefa de la Unidad de Microbiología del Campus Occidente de la Facultad de Medicina de la Universidad de Chile siendo al mismo tiempo Jefa del Laboratorio de Microbiología del Hospital San Juan de Dios. Desde ese entonces comienza 
su gran tarea abocada principalmente a la difusión y conocimiento de la Microbiología, dándole una orientación clínica, estimulada por los profesores de Medicina Drs. Rodolfo Armas Cruz y Esteban Parrochia, siendo pionera en la formación de esta especialidad que hoy en día es ampliamente reconocida. Fue asesora en el Servicio de Salud Metropolitano Occidente del Programa de Tuberculosis, y del Ministerio de Salud como integrante de la Comisión Nacional de SIDA.

Merece especial mención su valioso aporte a la problemática de las infecciones nosocomiales y siendo miembro de la Comisión Nacional de Infecciones Intrahospitalarias (IIH), fue uno de los primeros médicos en promover esta disciplina y formar a otros profesionales en esta importante materia que actualmente es fundamental en todos los hospitales.

Entre los años 1995 y 1998 fue Directora del Departamento y luego del Programa de Microbiología y Micología en el Instituto de Ciencias Biomédicas de la Facultad Medicina. Posteriormente fue elegida Directora de la Escuela de Postgrado de esta misma facultad, cargo que ejerció durante ocho años con gran entusiasmo, seriedad y responsabilidad, siendo ampliamente valorada en su excelente gestión por becados y académicos. En este período es presidente del Comité Nacional de Acreditación de Postítulo e integra las comisiones de Coordinación de Grados Académicos, Planificación Estratégica y Doctorado en Ciencias Médicas y Especialidades. Miembro por más de 10 años de la Corporación Nacional de Certificación de Especialista, (CONACEM) logra el reconocimiento por esta institución de la especialidad de Microbiología. En el 2006 deja la Escuela de Postgrado y se hace cargo de la Jefatura del Servicio de Laboratorio Clínico del Hospital Clínico de la Universidad de Chile, el cual ejerce hasta el momento.

Sin lugar a dudas, la docencia es lo suyo. Definitivamente lo que la hace más feliz es hacer clases a sus queridos alumnos, ya sea de pre o post grado, de cualquier profesión, nunca ha hecho diferencia. En pregrado formó en Microbiología y en Enfermedades Infecciosas a numerosos alumnos de Medicina, Enfermería, Obstetricia y Tecnología Médica. En postgrado es docente y Jefe del Programa de Formación de Especialistas en Microbiología y Laboratorio Clínico desde 1975 a la fecha. Ha formado más de 20 especialistas en Microbiología (listado adjunto) los que en su mayoría se desempeñan como Jefes de Laboratorio en los principales hospitales y clínicas del país y en los de comités de IIH. Todos quienes fueron sus alumnos comparten el "espíritu Dra. Pinto" es decir, amor por lo que hacemos.

Ha participado exitosamente en más de 100 cursos de postgrado en calidad de expositora y organizadora lo que la posiciona como referente de la especialidad en nuestro país y en el extranjero.
Microbiólogos discípulos de M. Eugenia Pinto C.

$\begin{array}{ll}\text { Becker Lisselotte } & \text { González Patricia } \\ \text { Broussain M. Teresa } & \text { Hervé Beatrice } \\ \text { Camponovo Rossana } & \text { Juliet Chrystal } \\ \text { Castillo Loriana } & \text { Quintana Verónica } \\ \text { Céspedes Alejandra } & \text { Lafourcade Mónica } \\ \text { Cona Erna } & \text { Nercelles Patricio } \\ \text { Correa Sonia } & \text { Porte Lorena } \\ \text { Elgueta Andrea } & \text { Rioseco María Luisa } \\ \text { Enríquez Nancy } & \text { Rojas Pamela } \\ \text { Fernández Alejandra } & \text { San Martín Marcela } \\ \text { Gómez Orietta } & \text { Silva Francisco }\end{array}$

En 1983 promueve en conjunto con especialistas de Medicina Interna y Pediatría la fundación de la Sociedad Chilena de Infectología, siendo posteriormente su Presidente entre 1991 y 1993 y miembro del directorio hasta 1995. Dentro de esta sociedad crea el Comité de Resistencia Antimicrobiana y el de Microbiología Clínica. Conjuntamente con el origen de la Sociedad se crea la Revista Chilena de Infectología, publicación oficial de esta sociedad siendo miembro activo hasta la actualidad del Comité Editorial.

En reconocimiento a sus méritos académicos y su gran prestigio es nombrada Presidente de la Asociación Chilena de Microbiología en 1985, en 1990 miembro del Comité Ejecutivo de la Internacional Society of Chemoterapy y Fellow of American College of Physicians siendo en el 2006, la primera mujer elegida como Gobernadora para el Capítulo Chileno de esta misma institución, cargo que ejercerá hasta el 2012. Además nos llena de orgullo su denominación "Mujer Siglo XXI" por la Universidad de Chile en el año 2004.

Cabe destacar su valioso aporte a la investigación en los temas de Microbiología, Infectología y antimicrobianos en revistas nacionales e internacionales, siendo su principal línea de investigación la resistencia antimicrobiana y las IIH.

La Dra. Pinto es admirada por todos los que la conocen por su sobresaliente inteligencia, su amplio conocimiento en diversos temas, tanto específicos como universales, su gran capacidad de organización y, en especial por sus alumnos, por sus innumerables cualidades como docente.

Con su ejemplo y sabiduría ha destacado a la Microbiología Clínica como una especialidad fundamental en la Infectología y en diversas disciplinas de la Medicina.

¡Gracias Dra. Pinto! 